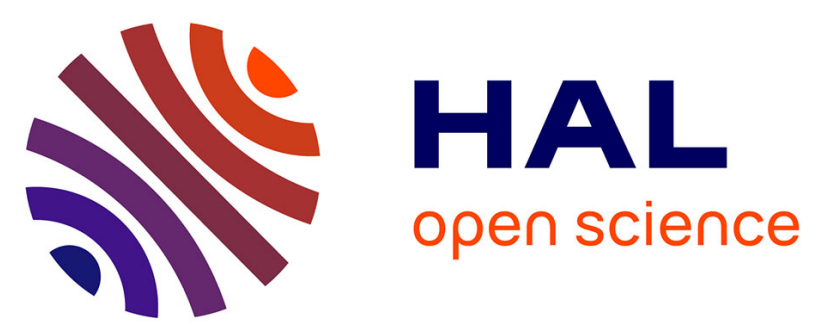

\title{
Evidence for bisphenol A-induced disruption of maternal thyroid homeostasis in the pregnant ewe at low level representative of human exposure
}

Davy Guignard, Véronique V. Gayrard-Troy, Marlène Z. Lacroix, Sylvie Puel, Nicole Picard-Hagen, Catherine Viguié

\section{To cite this version:}

Davy Guignard, Véronique V. Gayrard-Troy, Marlène Z. Lacroix, Sylvie Puel, Nicole Picard-Hagen, et al.. Evidence for bisphenol A-induced disruption of maternal thyroid homeostasis in the pregnant ewe at low level representative of human exposure. Chemosphere, 2017, 182, pp.458-467. 10.1016/j.chemosphere.2017.05.028 . hal-01607369

\section{HAL Id: hal-01607369 \\ https://hal.science/hal-01607369}

Submitted on 26 May 2020

HAL is a multi-disciplinary open access archive for the deposit and dissemination of scientific research documents, whether they are published or not. The documents may come from teaching and research institutions in France or abroad, or from public or private research centers.
L'archive ouverte pluridisciplinaire HAL, est destinée au dépôt et à la diffusion de documents scientifiques de niveau recherche, publiés ou non, émanant des établissements d'enseignement et de recherche français ou étrangers, des laboratoires publics ou privés. 


\section{Accepted Manuscript}

Evidence for bisphenol A-induced disruption of maternal thyroid homeostasis in the pregnant ewe at low level representative of human exposure

Davy Guignard, Véronique Gayrard, Marlène Lacroix, Sylvie Puel, Nicole PicardHagen, Catherine Viguié

PII: S0045-6535(17)30723-3

DOI: 10.1016/j.chemosphere.2017.05.028

Reference: CHEM 19243

To appear in: Chemosphere

Received Date: 10 January 2017

Revised Date: 28 April 2017

Accepted Date: 04 May 2017

Please cite this article as: Davy Guignard, Véronique Gayrard, Marlène Lacroix, Sylvie Puel, Nicole Picard-Hagen, Catherine Viguié, Evidence for bisphenol A-induced disruption of maternal thyroid homeostasis in the pregnant ewe at low level representative of human exposure, Chemosphere (2017), doi: 10.1016/j.chemosphere.2017.05.028

This is a PDF file of an unedited manuscript that has been accepted for publication. As a service to our customers we are providing this early version of the manuscript. The manuscript will undergo copyediting, typesetting, and review of the resulting proof before it is published in its final form. Please note that during the production process errors may be discovered which could affect the content, and all legal disclaimers that apply to the journal pertain. 
1 Evidence for bisphenol A-induced disruption of maternal thyroid homeostasis in the

2 pregnant ewe at low level representative of human exposure

3 Davy Guignard, Véronique Gayrard, Marlène Lacroix, Sylvie Puel, Nicole Picard-Hagen,

4 Catherine Viguié

5 Toxalim (Research Centre in Food Toxicology), Université de Toulouse, INRA, ENVT, INP-

6 Purpan, UPS, Toulouse, France

7

8 Corresponding author: Catherine Viguié

9 TOXALIM UMR 1331, INRA UPS

10 Ecole Nationale Vétérinaire de Toulouse

1123 chemin des Capelles, BP 87614

1231076 Toulouse cedex3, France

13 Phone: +33561193913

14 Email: catherine.viguie@,inra.fr

15

16 
Many uncertainties remain regarding the potential of bisphenol A (BPA) as a thyroid disruptor in mammals and the relevance of experimental data to humans. The relevance of the exposure schemes used in experimental in vivo studies is also a major source of uncertainty when analysing the risk of BPA exposure for human health. In this context, the goals of our study, conducted in an ovine model relevant to human gestation and thyroid physiologies, were to: 1) determine the equivalence of subcutaneous and dietary exposures and 2) determine if environmentally relevant doses of BPA can alter gestational and newborn thyroid functions. The difference between the two routes of exposure was mainly related to the overall BPA exposure and much less to the peak serum concentrations. Interestingly, BPA-GLUC (the main metabolite of BPA) internal exposure via both routes was almost identical. The decrease in thyroid hormones concentration overtime was more accentuated in ewes treated with BPA, particularly with the medium dose $(50 \mu \mathrm{g} /(\mathrm{kg} . \mathrm{d})$; $\mathrm{SC})$ for which the maximum BPA concentrations were predicted to be within the $1-10 \mathrm{ng} / \mathrm{mL}$ range i.e. very similar to the highest blood concentrations reported in humans. The balance between TT4 and rT3 varied differently between the vehicle and the medium dose group. The mechanisms underlying those modifications of maternal thyroid homeostasis remain to be determined. Our study did not evidence significant modification of TSH secretion or binding to serum proteins but might suggest an effect at the level of deiodinases.

\section{Highlights}

- Maximum BPA serum concentration is similar between subcutaneous and dietary routes

-Bisphenol A alters the maternal thyroid status in pregnant ewe

-Thyroid disruption is observed at BPA serum concentration relevant to human exposure 
41 -BPA might disrupt the deiodinase activity in pregnant ewe

\section{Abbreviations:}

43 AUC, area under the curve; BPA, bisphenol A; BPA-GLUC, bisphenol A glucuronide; BPA-

44

45 SULF, bisphenol A sulfate; Cmax, maximum concentration; GD, gestational day; LOQ, limit of quantification; LOD, limit of detection; PK, pharmacokinetic; PND, post-natal day; rT3, reverse triiothyronine; S.C., subcutaneous; TH, thyroid hormones; TSH, thyroid stimulating hormone; TT3, total triiothyronine; TT4, total thyroxine; fT4, free thyroxine.

$\underline{\text { Keywords: }}$ bisphenol A; toxicokinetic; exposure; thyroid disruption; pregnancy; ovine model 
Bisphenol A (BPA), a major molecule used in the plastics industry, is now recognized to be an endocrine disruptor that exerts deleterious effects on human health (Chapin et al., 2008; vom Saal et al., 2007). Most investigations have focused on reproductive functions based on the estrogenomimetic properties of this compound. However, accumulated evidence suggests that BPA might have negative effects on other endocrine systems (Richter et al., 2007; Rubin, 2011) including thyroid function (Zoeller, 2010).

Although sometimes controversial, the results of numerous epidemiological studies in humans indicate that BPA exposure might be associated with diverse degrees of thyroid disruption in adults, children and new born. Epidemiological data obtained in a cohort of men from infertile couples (Meeker et al., 2010) and in a larger cohort of healthy individuals (NHANES cohort; Meeker and Ferguson, 2011) suggest that BPA exposure might be associated with some degrees of thyroid disruption characterized by an inverse relationship between urinary BPA concentrations and total thyroxine (TT4) concentrations. In another cohort of adults, urinary BPA concentration was, respectively, positively and negatively correlated with free $\mathrm{T} 3$ and TSH serum concentrations (Wang et al., 2013). In a large cohort of Thai adults, BPA serum concentrations were shown to be negatively correlated with free T4 (fT4) concentrations in men but not in women (Sriphrapradang et al., 2013). In a cohort of 9 to 11 year old Chinese children, the BPA urinary concentration in morning spot sampling was negatively correlated with thyroid gland volume (Wang et al., 2015) and this correlation did not seem to depend upon the iodine supply and/or iodine status of the children.

As far as gestational exposure is concerned, data are very scarce in human. However, there is some evidence that infant thyroid function might be altered in relation to maternal exposure to BPA. In a cohort of pregnant women and their infants (CHAMACOS study), urinary BPA in 
the mother was shown to be negatively correlated with maternal TT4 blood concentration when the urine BPA and TT4 blood samples were collected close together in time (Chevrier et al., 2013). As a result, the average maternal urinary BPA was related to increased odds of low TT4 in the mother. An inverse relationship between maternal urinary BPA and neonatal blood TSH was evidenced in newborn boys. In the HOME study, 26-week maternal urinary BPA concentrations were inversely correlated with serum TSH concentrations in newborn girls but not in boys (Romano et al., 2015).

Very few experimental studies have been done on the effect of BPA on thyroid function in mammals. In one study, the physiological increase in circulating TT4 that generally occurs around post-natal day 15 (PND15) was amplified in rats born to and fed by mothers treated with an oral BPA dose of $1 \mathrm{mg} /(\mathrm{kg} . \mathrm{d})$ from gestational day (GD) 6 until weaning (Zoeller et al., 2005). In another study in pregnant rats (Xu et al., 2007), BPA oral treatment of $0.1 \mathrm{mg} / \mathrm{L}$ in drinking water (approximately $10 \mu \mathrm{g} /(\mathrm{kg} . \mathrm{d})$ ) led to a transitory decrease in fT4 concentration in mothers during the early postpartum period (PND0 to PND7), while their male offspring showed an increase in fT4 at PND7 followed by a decrease at PND21.

The relevance to humans of thyroid regulation in rodents is nevertheless controversial due to the different timing of thyroid function ontogenesis and the lack of expression of thyroxine binding globulin (TBG), the high affinity specific binding protein in adult rats (Fisher et al., 1976).This serum protein is considered a key player in the maintenance of thyroid homeostasis (Hard, 1998; Wu and Farrelly, 2006). Ovine model is considered as a more relevant model to human than rodents from the thyroid regulation standpoint. Indeed, in this species as in human, TBG is the major serum carrier protein of thyroid hormones. Furthermore, ovine and human species are both considered as precocious species for the ontogenesis of the thyroid system because fetal thyroid axis is almost mature at birth. In sheep, thyroid gland can accumulate iodine and synthesize $\mathrm{T} 4$ around the $70^{\text {th }}$ day of gestation, the neuroendocrine control of the 
thyroid axis starts to develop as soon as the $50^{\text {th }}$ day of gestation (Fisher et al., 1976) and TH receptor expression is observable around 80 days of gestation in the brain and the liver (Polk et al., 1989). T3 levels in blood are much lower in the fetus than in the mother and start to rise significantly only on the very late stages of pregnancy in both human (Fisher et al., 2002) and sheep (Fisher et al., 1994).

In one of our studies in pregnant ewes, BPA exposure was associated with hypothyroxinemia (about 30\% decrease in TT4) in both the mothers and newborn lambs after subcutaneous exposure of the ewes to $5 \mathrm{mg} /(\mathrm{kg} . \mathrm{d})$ throughout gestation (Viguié et al., 2013).

Evidence that BPA can be a potential thyroid disruptor has also arisen from studies in mammalian cells and in amphibian or fish larvae models. The results of these studies converge to suggest that BPA can exert an antagonistic effect on TH-dependent mechanisms (Fini et al., 2007; Goto et al., 2006; Heimeier et al., 2009; Iwamuro et al., 2003; Kaneko et al., 2008; Sun et al., 2009; Terrien et al., 2011; Yang and Chan, 2015) and that several pathways involved in TH economy can be affected by BPA. Hepatic regulation of thyroid hormone homeostasis can also be affected by BPA as shown in a zebrafish liver cell line in which BPA $(45-180 \mu \mathrm{M})$ decreased the expression of several genes involved in thyroid homeostasis i.e., deiodinases I and III, sulfotransferases 1,2 and 3, UGT2A1 and thyroid receptor $\beta$ (Yang and Chan, 2015). In addition, the antagonistic effect of BPA could be mediated, at least in cell models, by the increased recruitment of co-repressors of $\mathrm{TH}$ nuclear receptors from the N-CoR family (Moriyama et al., 2002; Sheng et al., 2012).

Overall, it is apparent that uncertainties remain regarding the potential of BPA as a thyroid disruptor in mammals and the relevance of experimental data to humans. Another major source of uncertainty on BPA risk analysis for human health based on experimental data obtained in animals is related to the level of internal exposure, particularly with regard to the route of 
administration. Indeed, in many good quality experimental studies, animals were exposed via parenteral or gastric gavage routes to ensure better control of the dose administered although none of these routes is totally representative of the acknowledged main route of human exposure i.e. via food contamination (Guignard et al., 2016; Taylor et al., 2011; Vom Saal et al., 2014). Thus, the relevance of the route of administration is a critical issue that every scientist needs to bear in mind when performing toxicological evaluations of small lipophilic molecules which, alike BPA, are subjected to a high hepatic first pass effect.

In this context, the goals of our study conducted in an ovine model relevant to human gestation and thyroid physiologies were to 1) determine the equivalence of subcutaneous and dietary exposures and 2) determine if environmentally relevant doses of BPA can alter gestational and newborn thyroid functions.

\section{Materials and Methods}

\subsection{Chemicals}

Bisphenol A 99\% purity (Sigma-Aldrich, Saint-Quentin Fallavier, France) was dissolved in corn oil / absolute ethanol (6/1: V/V). For experiment 1, a single BPA solution $(100 \mathrm{mg} / \mathrm{mL})$ was prepared and used for both routes of administration. The volume administered to the animals was adjusted to the bodyweight recorded the day before the administrations. For the dietary route, BPA solution was spilled onto the pellet ration (on average $6 \mathrm{~mL}$ of solution on $75 \mathrm{~g}$ of pellets). The subcutaneous (S.C.) injection of BPA was performed on the distal part of the neck (on average $3 \mathrm{~mL} / \mathrm{ewe}$ ). For experiment 2, a vehicle and three different BPA solutions $(0.01-1$ and $100 \mathrm{mg} / \mathrm{mL})$ were prepared so that the injected volume adjusted to individual bodyweight was the same in all groups. The solutions were renewed monthly and were stored at ambient temperature in sealed amber glass bottles for the entire duration of their use. The 
147

148

149

150

151

152

153

154

155

156

157

158

159

160

161

162

163

164

165

166

167

168

vehicle solution was prepared and stored in a different room. All material used for the solution preparation, sample processing and assays was either made of glass or of BPA-free plastics.

\subsection{Animal husbandry}

All animal procedures were carried out in accordance with the accepted standards of humane animal care under agreement 311155515 for animal experimentation from the French Ministry of Agriculture and validated by the local ethical committee for animal experimentation (project number: 20160323 10542323) and by the French Ministry of Higher Education and Research (project number: 00890.01) for experiments 2 and 1, respectively. The study was performed on adult Lacaune ewes in the sheep research facility at the National Veterinary School of Toulouse, France. The ewes were kept under natural photoperiodic and temperature conditions, with free access to water, hay ad libitum and plant based pellets (Brebilac ${ }^{\circledR}$ RAGT, Rodez, France). The absence of BPA contamination of water, hay and pellets was checked by assaying BPA in 100 mg samples of each matrix homogenized in $1 \mathrm{~mL}$ of acetonitrile. BPA was not detected in any of the samples (LOD $10 \mathrm{ng} / \mathrm{g}$ of food).

In experiment 1 , animals were penned individually the day before the administrations and for $24 \mathrm{~h}$ following administrations. For experiment 2, all animals in a same group were kept together and no direct contact was allowed between animals from different groups, with separate food and water supplies provided for each group.

\subsection{Experimental design}

Experiment 1: relative bioavailability via subcutaneous and dietary routes of administration 
169

170

171

172

173

174

175

176

177

178

179

180

181

182

183

184

185

186

187

188

189

190

191

This experiment was designed to evaluate the equivalence, in terms of internal exposure to BPA, of the S.C. route of administration used for convenience in this experiment and the dietary one thought to be the main route of exposure in human populations. It was conducted on 4 ewes (3-5 year old; 50-73 kg) and was divided into 2 periods conducted at least 13 days apart. The first period was devoted to the S.C. route of administration ( $5 \mathrm{mg} / \mathrm{kg}$ of body weight). During the second period, the same ewes received BPA via the diet (10 mg/kg of body weight). Before the dietary period, ewes were fasted overnight to facilitate intake of the BPA-treated pellets. The ewes ingested the pellets within $2-9$ minutes. Free access to hay and water was maintained after the administrations. The different doses for the different routes were based on previous studies and were chosen to produce BPA concentrations above our assay limit of quantification, for at least 8-10 hours after the administrations. Use of different doses for the two routes was possible because there is evidence that the parameters of BPA pharmacokinetics in several species including sheep are linear functions of the dose (Collet et al., 2010; Taylor et al., 2011; Tominaga et al., 2006) over a dose range of 5 to $10 \mathrm{mg} / \mathrm{kg}$. Results regarding the dietary route have been described in detail in a previous publication (Guignard et al., 2016).

Serial jugular blood samples were collected before all administrations and $0.5-1-2-4-6-$ $8-10-24 \mathrm{~h}$ after the S.C. administration or $0.03-0.08-0.16-0.25-0.5-1-2-4-6-8$ $-10-26 \mathrm{~h}$ after the dietary exposure. For the dietary administration, time 0 was the time when the ewes had finished ingesting the pellets. The blood samples were centrifuged at $3000 \mathrm{~g}$ at $4^{\circ} \mathrm{C}$ for $20 \mathrm{~min}$, then the serum was decanted and stored in propylene tubes at $-20^{\circ} \mathrm{C}$ until assayed.

Experiment 2: Effect of environmentally relevant doses of BPA on maternal and fetal thyroid status. 
192

193

194

195

196

197

198

199

200

201

202

203

204

205

206

207

208

209

210

211

212

213

214

215

This experiment was conducted on 22 pregnant ewes (1-3 year old; 55-103 kg) artificially inseminated on the same day after hormonal synchronization of estrus. A vitamin and iodine/selenium-enriched mineral supplement (Alimal gestante ${ }^{\circledR}$ Alliance Elevage, Souvigny, France) was provided to cover the specific requirements of gestation. The ewes were weighed twice a month. The amount of pellets was regularly adjusted to pregnancy requirements and changes in body weight. The ewes were randomly allocated to 4 treatment groups balanced for TT4 concentration, body weight and age. From GD28 to GD132-134, each group received different daily doses of BPA by S.C. administration i.e., low dose group $0.5 \mu \mathrm{g} /(\mathrm{kg} . \mathrm{d})(\mathrm{n}=6)$; medium dose group $50 \mu \mathrm{g} /(\mathrm{kg} . \mathrm{d})(\mathrm{n}=5)$; high dose $5000 \mu \mathrm{g} /(\mathrm{kg} . \mathrm{d})(\mathrm{n}=5)$ and vehicle group $(n=6)$. The administered volume was regularly adjusted to the most recently recorded body weight.

Maternal blood samples were collected twice a week during the treatment period, just before the next BPA administration. The first maternal blood sample was taken on GD28 before the first BPA or vehicle administration. On GD62, serial blood samples were collected from animals in the high dose treatment group ( $0-1.5-4-8$ and $10 \mathrm{~h}$ post administration).

At GD133-135, i.e. about two weeks before the expected term, the fetuses were delivered by cesarean section under rachianesthesia and local anesthesia of the muscle wall $(5 \mathrm{~mL}$ of lidocaine in the sacrolombar space and $10 \mathrm{~mL}$ along the incision line on the abdominal wall; Lurocaine ${ }^{\circledR}$, Vetoquinol SA, Lure, France) to avoid spontaneous deliveries. Although not totally mature at this age, thyroid function is already well established at this stage in the sheep as in human.

Maternal and fetal jugular blood, cord blood and amniotic fluid were collected at delivery after which the ewes and fetuses were immediately euthanized by intravenous overdose of sodium pentobarbital (Doléthal®, Vetoquinol France, $60 \mathrm{mg} / \mathrm{kg}$ of pentobarbital i.v.). 
BPA, BPA-GLUC and BPA-SULF (BPA sulfate) concentrations were simultaneously

219

220

221

222

223

224

225

226

227

228

229

230

231

232

233

234

235

236

237

238

239

measured in the serum samples collected during experiment 1 , in the amniotic fluid, cord blood and maternal and fetal blood samples collected at delivery, and in the serial samples collected from the high dose group in experiment 2, using a previously described UPLC/MS/MS method (Lacroix et al., 2011). The validated LOQs were $1 \mathrm{ng} / \mathrm{mL}$ for BPA and $5 \mathrm{ng} / \mathrm{mL}$ for BPAGLUC/S. The mean intra- and inter-day coefficients of variation for three concentration levels of BPA and BPA-GLUC were lower than $15 \%$.

\subsection{Pharmacokinetic analyses}

All pharmacokinetic analyses were performed with the Phoenix ${ }^{\circledR}$ software, version 6.4 (Pharsight Corporation, Cary, NC, USA).

\section{Experiment 1:}

Serum concentration-time profiles of BPA and BPA-GLUC were first analyzed using a noncompartmental approach. The areas under the BPA and BPA-GLUC serum concentrations curves (BPA and BPA-GLUC $\mathrm{AUC}_{\text {last}}$ ) were calculated using the linear trapezoidal rule from dosing time to the last quantifiable (i.e. > LOQ) serum concentration sampling time. The AUC from $\mathrm{t}=0$ to infinity was obtained by adding to $\mathrm{AUC}_{\text {last }}$ the area extrapolated from the last observation to infinity obtained by dividing the last observed quantifiable serum concentration by the slope of the terminal phase estimated by linear regression, using the best fit option of Phoenix ${ }^{\circledR}$. As previously explained (Gayrard et al., 2013; Guignard et al., 2016), to avoid any confusion due to high concentration resulting from direct drainage of the mouth by the jugular 
veins, the data obtained during the first 10 minutes after final pellet ingestion were not taken into account in the calculation of BPA AUC ${ }_{\text {inf. }}$ The digestive absorption of BPA being close to $100 \%$ (Doerge et al., 2010), the molar ratio $\mathrm{AUC}_{\text {inf }} \mathrm{BPA}-\mathrm{GLUC} / \mathrm{AUC}_{\text {inf }} \mathrm{BPA}$ could be used as an index of BPA metabolism. The relative bioavailability of BPA by dietary and subcutaneous routes was compared using the following equation:

$$
\text { Relative bioavailability }=\frac{B P A \text { AUCinf diet }}{B P A \text { AUCinf S.C. }} X \frac{B P A \text { dose S.C. }}{B P A \text { dose diet }}
$$

The time courses of serum BPA concentrations obtained in the 4 ewes after the S.C. administration were fitted to a triexponential equation, corresponding to an extravascular administration, to generate the pharmacokinetic (PK) parameters required to predict the time course of BPA blood concentrations for the lowest doses in experiment 2:

$$
C(t)=A \cdot e^{-\alpha . t}+B \cdot e^{-\beta . t}+C \cdot e^{-K 01 . t}
$$

\section{Experiment 2:}

Given the known BPA PK parameters and our assay LOQ, the maternal serum concentrations of BPA were likely to be non-quantifiable after repeated S.C. administrations of BPA at 0.5 or $50 \mu \mathrm{g} /(\mathrm{kg} . \mathrm{d})$. Time-concentration profiles of BPA were therefore simulated, using the PK parameters and the model of experiment 1 , to estimate the animal internal exposure. BPA disposition was assumed to be linear overtime, as no accumulation or increase in the metabolism of BPA or BPA-GLUC had been observed with repeated administrations (Collet et al., 2010; Viguié et al., 2013) and because gestation does not affect BPA metabolic rate in the ewe (Corbel et al., 2013). The goodness-of-fit was determined using data obtained from the serial samples collected from ewes receiving the highest dose at GD62. 
264

265

Total and free T4and total T3 concentrations were measured in one every two samples collected twice a week in ewes from GD28 to GD128 and from fetal jugular samples collected at delivery using a RIA kit (T4 MAb RIA kit, MP Biomedicals, Illkirch, France). The LOQ of the RIA assays (lowest value with an intra-assay CV lower than $20 \%$ and an accuracy above $90 \%$ ) was validated at $10 \mathrm{ng} / \mathrm{mL}$ and $0.4 \mathrm{ng} / \mathrm{mL}$ for total $\mathrm{T} 4$ andT3, respectively. For free $\mathrm{T} 4$, a limit of sensitivity was set at the lowest concentration of the standard curve providing that the intra-assay CV was below $20 \%(3.2 \mathrm{pg} / \mathrm{mL})$. The mean intra- and inter-assay CVs for three QC pools were systematically below $10 \%$.

The balance between T4 activation into T3 and its inactivation to rT3, through different deiodinase activities, particularly within the placenta, has a key role in ensuring adequate $\mathrm{TH}$ supply to the fetus to meet its needs. We therefore used a previously described UPLC/MS/MS assay (Roques et al., 2012) to simultaneously determine TT4 and rT3 concentrations in the cord blood samples and in maternal samples collected after TT4 modification had been established, at GD $41-44-48-51-55-58-72-86-100-114$ and 128 . The LOD for each assay run was defined as the calculated concentration corresponding to a peak area at a given elution time, equal to three fold the area obtained by solvent injection. These LOD were 2.8, 0.5 and $0.15 \mathrm{ng} / \mathrm{mL}$ for TT4, rT3 and TT3, respectively. Mean intra- and inter-assay CVs for three QC pools were systematically below 15\% and accuracy was between 88 and 108\%. To determine the consistency between RIA and UPLC/MS assays, we assayed TT4 in a pool of 43 fetal sheep blood samples from another experiment using both methods. We found a mean inter-method coefficient of variation of $5.2 \%$ for concentrations ranging from 53 to 138 $\mathrm{ng} / \mathrm{ml}$. 
TSH serum concentration was measured in maternal samples collected at GD 34-65 - 97 and

Statistical analyses were performed with Systat ${ }^{\circledR}$ (Systat Software Inc., San Jose California,USA).

For experiment 1, mean AUC and Cmax for both BPA and BPA-GLUC concentrations were compared using paired T-tests.

297

For experiment 2, the effect of the treatment on the time course of maternal TT4, fT4, TT3 and TSH was analyzed by using a two-way repeated-measures ANOVA, with time, treatment and their interaction as fixed factors and animals nested in the treatment as a random effect factor. A Bonferroni test was performed to identify the dose that individually would give a different serum $\mathrm{TH}$ profile to the one observed in the control group.

The effect of the treatment on hormone concentrations measured in fetal and maternal blood at delivery was analyzed with a one-way ANOVA.

\section{$\underline{\text { 3. Results }}$}

3.1. Relative bioavailability by subcutaneous and dietary routes of administration $\underline{(\text { Experiment 1) }}$

Fig. 1 (A-B) shows the mean ( \pm S.E.M.) serum BPA and BPA-GLUC concentration-time profiles following S.C. $(5 \mathrm{mg} / \mathrm{kg})$ or dietary $(10 \mathrm{mg} / \mathrm{kg})$ administration of BPA. The 
concentrations were not normalized by the dose. The concentration-time profiles varied greatly

311

312

A)



B)

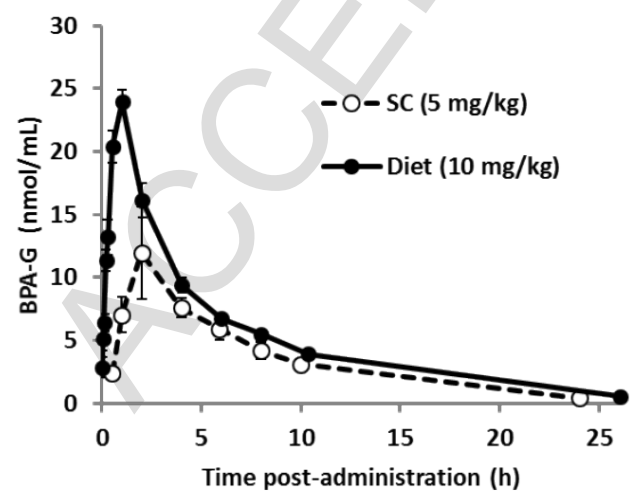

C)

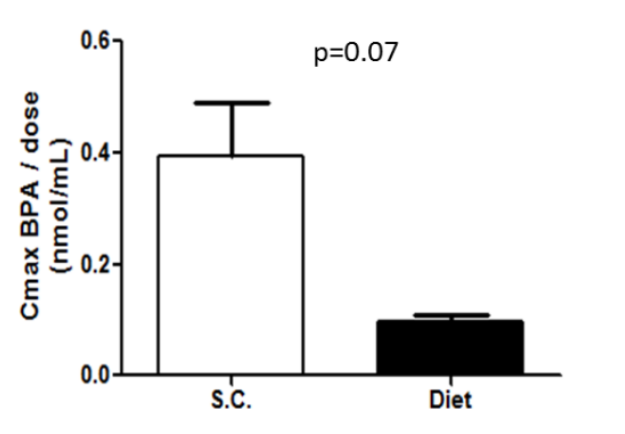

D)


$4.6 \pm 1.5$ fold higher than for the dietary route $(p=0.07$; Fig. $1 \mathrm{C})$. By contrast to BPA, the BPA-GLUC concentration time course for the two routes of exposure was very similar and the maximum concentration attained with both routes, when normalized by the administered dose, was about $2.4 \mathrm{nmol} / \mathrm{mL}$ (Fig. $1 \mathrm{D})$. 
administrations. Blood samples were collected $0.5-1-2-4-6-8-10$ and $24 \mathrm{~h}$ after subcutaneous administration and $0.03-0.08-0.16-0.25-0.5-1-2-4-6-8-10$ and 24 $\mathrm{h}$ after dietary administration. The serum concentrations were not normalized by the dose. $\mathrm{C}$ D) Mean ( \pm S.E.M.) maximum concentration of BPA (C) and BPA-GLUC (D) normalized by the BPA dose obtained after subcutaneous and dietary administrations.

Administration by S.C. route led to a higher overall internal exposure to BPA characterized by a much higher normalized by the dose $\mathrm{AUC}_{\text {inf }}(\mathrm{p}=0.002$; Fig. $2 \mathrm{~A}$ ). The calculated relative bioavailability of BPA for the dietary as compared to S.C. route was $3.3 \pm 0.3 \%$. The $\mathrm{AUC}_{\text {inf }}$ of BPA-GLUC was very similar for both routes of administration ( $p=0.11$; Fig. 2 B). The ratio

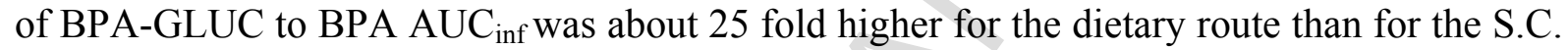
route ( $\mathrm{p}=0.002$; Fig. $2 \mathrm{C}$ ). This can be explained by the extensive hepatic first-pass effect that immediately transforms BPA into BPA-GLUC after BPA intestinal absorption.

A)

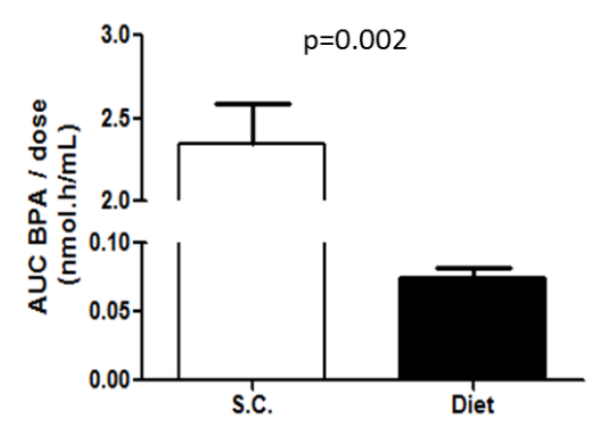

B)

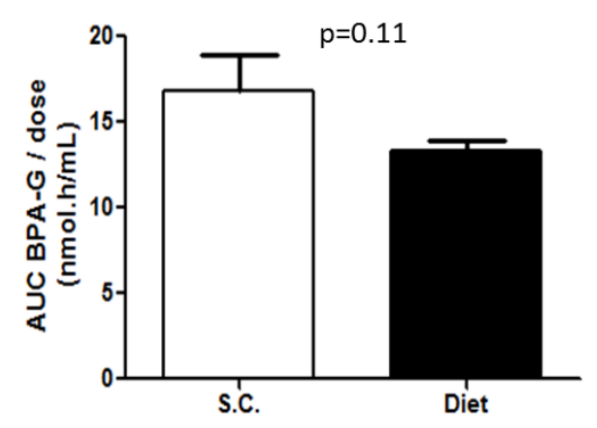

C)

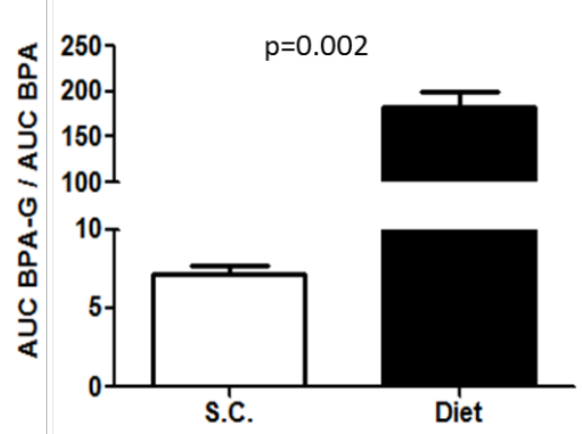


Fig. 2: A-B) mean ( \pm S.E.M.) $\mathrm{AUC}_{\text {inf }}$ of BPA (A) and BPA-GLUC (B) concentrations

339

340

341

342 normalized by the BPA dose obtained after subcutaneous $(5 \mathrm{mg} / \mathrm{kg})$ and dietary $(10 \mathrm{mg} / \mathrm{kg})$ administrations in the same ewes $(n=4)$. The BPA concentrations obtained during the first 10 minutes after the end of food intake were not taken into account in the AUC estimation. C) Mean ( \pm S.E.M.) ratio of the BPA to the BPA-GLUC molar dose-normalized $\mathrm{AUC}_{\mathrm{inf}}$ after subcutaneous and dietary administrations.

Overall, the maximum serum concentration of BPA obtained after subcutaneous administration was not dramatically higher than after dietary administration. However, BPA high level exposure was more prolonged after administration by S.C. route than by dietary route. Interestingly, the internal exposure to BPA-GLUC after both routes of administration was almost identical.

\subsection{Maternal and fetal monitoring of BPA and BPA-GLUC internal exposure (Experiment}

2)

Table 1 describes the mean BPA, BPA-GLUC and BPA-SULF concentrations measured in the maternal and fetal jugular blood, cord blood and amniotic fluid collected at delivery for the medium and high BPA dose groups. Concentrations were below the assay LOQ in all samples from the control group. BPA concentrations were quantifiable in all collected blood samples only for animals in the highest dose group and in the amniotic fluid from the medium and high dose groups. It was quantifiable in cord blood samples from 4/10 and5/10 lambs from the low and medium dose groups, respectively. BPA-GLUC concentrations could be systematically measured in fetal jugular blood, cord blood and amniotic fluid samples from the medium and high dose groups and in a few fetal jugular (5/10), cord blood (3/10) and amniotic fluid (3/7) 
samples from the low dose group. Overall, BPA-GLUC concentrations in the fetal compartment were much higher than the BPA fetal concentrations or the BPA-GLUC maternal concentrations. BPA was detectable in the maternal blood only for the highest dose group. BPAGLUC in the maternal blood was detectable in a few samples of the low and medium doses groups and was systematically quantified in all the ewes from the high dose group. When quantifiable, BPA maternal concentrations were very similar to the amniotic ones, while for BPA-GLUC amniotic fluid concentrations were much higher than the maternal ones and within the same range of the fetal ones.

BPA-SULF could be measured in samples from the fetal compartment (jugular fetal and cord blood) in all samples from the medium and high dose groups. For the amniotic fluid and maternal samples, it was rarely measurable in samples from the medium dose group. In the fetal and cord blood samples from the high dose group, BPA-SULF was detected at levels about 50 to 80 fold higher than BPA and about 20 fold lower than BPA-GLUC. BPA-SULF concentration in amniotic fluid were about 10 fold lower than that in the fetus while they were about 10 fold higher than that of the maternal compartment. 
377 Table 1: mean ( \pm SEM) BPA and BPA-GLUC/S concentrations ( $\mathrm{nmol} / \mathrm{mL}$ ) measured in the

378 maternal and fetal jugular blood, cord blood and amniotic fluid after treatment of pregnant ewes

379 with BPA from GD 28 to 132-134. LOQ were validated at $1 \mathrm{ng} / \mathrm{mL}$ and $5 \mathrm{ng} / \mathrm{ml}$ for BPA and

380 BPA-GLUC/S, respectively $(4.4,12.4$ and 16.2nmol/L for BPA, BPA-GLUC and BPA-SULF,

381 respectively). Mean concentration were noted as " $<$ LOQ" when the concentrations in more than

382 half the samples were below LOQ. When BPA and/or its metabolites were measurable in at

383 least half the samples, the non-measurable values were replaced by the LOQ/2 for the mean

384 calculation.

\begin{tabular}{|c|c|c|c|c|c|c|c|c|c|c|c|c|c|}
\hline & \multicolumn{3}{|c|}{ Cord blood } & \multicolumn{3}{|c|}{ Fetal blood } & \multicolumn{3}{|c|}{ Amniotic fluid } & \multicolumn{3}{|c|}{ Maternal blood } \\
\hline \multirow{2}{*}{$\begin{array}{c}\text { Medium } \\
\text { dose } \\
50 \mu \mathrm{g} /(\mathrm{kg} . \mathrm{d}) \\
0.2 \\
\mu \mathrm{mol} /(\mathrm{kg} . \mathrm{d})\end{array}$} & Mean & 0.007 & 1.180 & 0.046 & $<$ LOQ & 1.09 & 0.040 & 0.012 & 0.284 & $<\mathrm{LOQ}$ & $<\mathrm{LOQ}$ & 0.022 & $<\mathrm{LOQ}$ \\
\hline & S.E.M. & 0.002 & 0.077 & 0.01 & & 0.058 & 0.006 & 0.005 & 0.034 & & & 0.008 & \\
\hline \multirow{3}{*}{$\begin{array}{c}\text { High dose } \\
5000 \\
\mu \mathrm{g} /(\mathrm{kg} . \mathrm{d}) \\
20 \\
\mu \mathrm{mol} /(\mathrm{kg} . \mathrm{d})\end{array}$} & Mean & 0.106 & 95.873 & 5.277 & 0.058 & 95.698 & 4.555 & 0.259 & 28.041 & 0.502 & 0.236 & 1.624 & 0.056 \\
\hline & S.E.M. & 0.012 & 11.540 & 0.766 & 0.005 & 14.422 & 0.454 & 0.055 & 2.582 & 0.206 & 0.030 & 0.153 & 0.005 \\
\hline & $\mathrm{n} / \mathrm{tot}$ & $8 / 8$ & $8 / 8$ & $8 / 8$ & 8.8 & $8 / 8$ & $8 / 8$ & $8 / 8$ & $8 / 8$ & $8 / 8$ & $5 / 5$ & $5 / 5$ & $5 / 5$ \\
\hline
\end{tabular}

385 
386

387

388

389

390

391

392

393

394

395

396

397

398

399

400

401

402

403

Fig. 3 shows the predicted BPA serum concentrations in ewes treated with BPA $(0.5-50$ or $5000 \mu \mathrm{g} /(\mathrm{kg} . \mathrm{d})$; S.C.) using a bi-compartmental model based on the PK parameters generated during experiment 1 . The values for BPA serum concentrations measured in a representative ewe from the $5000 \mu \mathrm{g} /(\mathrm{kg} . \mathrm{d})$ group at GD 62 were superimposed on the prediction curve and showed a good fitting of the data by our model. BPA serum concentrations were predicted to fluctuate between $2-32 \mathrm{pg} / \mathrm{mL}(8.8 \mathrm{pmol} / \mathrm{L}-0.14 \mathrm{nmol} / \mathrm{L})$, between $0.2-3.2 \mathrm{ng} / \mathrm{mL}(0.88-14$ $\mathrm{nmol} / \mathrm{L})$ and between $20-320 \mathrm{ng} / \mathrm{mL}(88-1400 \mathrm{nmol} / \mathrm{L})$ for the BPA doses of $0.5,50$ and 5000 $\mu \mathrm{g} /(\mathrm{kg} . \mathrm{d})$, respectively.



Fig. 3: predicted serum concentrations of BPA in pregnant ewes treated with repeated subcutaneous administrations of BPA $(0.5$ - 50 and $5000 \mu \mathrm{g} /(\mathrm{kg} . \mathrm{d}))$. Concentrations were predicted using a bi-compartmental model and appropriate pharmacokinetic parameters previously established in the ewe for a dose of $5 \mathrm{mg} /(\mathrm{kg} . \mathrm{d})$. Observed concentrations are the BPA serum concentrations measured in blood samples collected from one representative ewe treated with BPA (5000 $\mu \mathrm{g} /(\mathrm{kg} . \mathrm{d})$; S.C.) from GD 28 to 132-134. Blood samples were collected at GD 62 at time $0-1.5-4-8$ and $10 \mathrm{~h}$ after the S.C. administration.

\subsection{Maternal and fetal thyroid status (Experiment 2)}


404

405

406

407

408

409

410

411

412

413

414

415

416

417

418

419

420 No effect of BPA at any dose on serum TSH concentrations (Fig. 5) could be evidenced in

Fig. 4 shows the time course of mean totalT4, free T4and total T3 concentrations measured in the maternal serum samples throughout the treatment period for each BPA group compared individually to the control group. For total T4, no significant interaction between time and treatment could be evidenced $(\mathrm{p}=0.37)$.

The time course of maternal free T4 serum concentrations appeared to be affected by the treatments (interaction time $\mathrm{x}$ treatment, $\mathrm{p}<0.001$ ). A significant difference between the control group and the medium $(p=0.003)$ and high $(p=0.015)$ dose groups was observed which was characterized by a decrease in fT4 concentrations. Visual inspection of the graph indicates that this decrease was initiated around GD 40 (i.e. after about 12 days of treatment) in BPA-treated animals. The time course of the ratio of fT4 to TT4 concentrations in maternal blood was not modified by the treatment (interaction time* treatment, $\mathrm{p}=0.7$ ).

Throughout pregnancy, the time course of TT3 concentrations in the mothers was significantly affected by the treatment (interaction time $\mathrm{x}$ treatment, $\mathrm{p}=0.04$ ). The profile of the medium dose group differed from that of the control group $(\mathrm{p}=0.03)$. Overall, TT3 concentrations were lower in BPA-treated animals from GD 60-70 (visual inspection). This interaction was not significant for the high dose group $(\mathrm{p}=0.44)$. 421 maternal blood samples collected at GD 34, 65,97 and 132 (interaction time * treatment, $\mathrm{p}=0.23$ 422 and treatment effect $\mathrm{p}=0.19)$. 

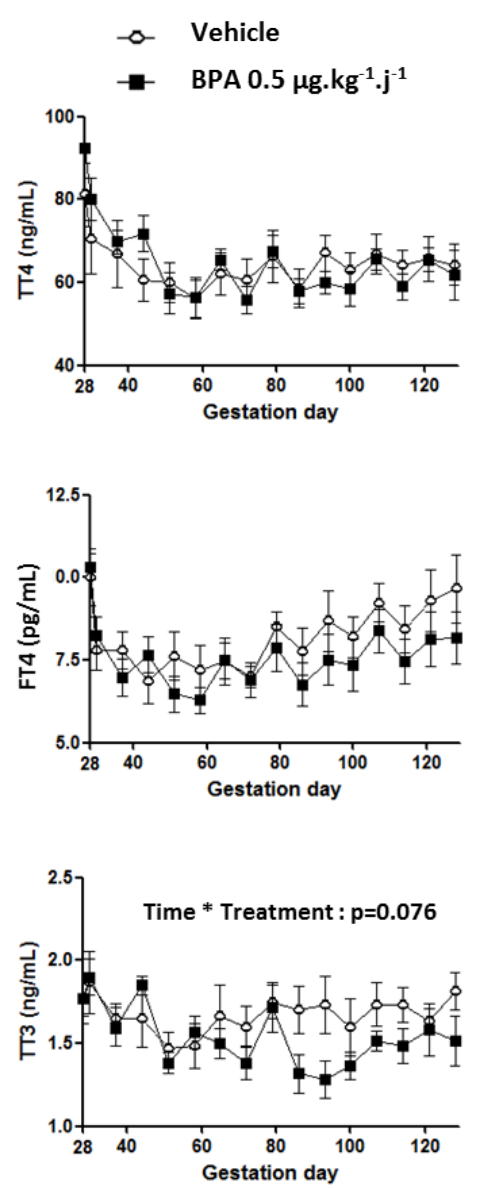
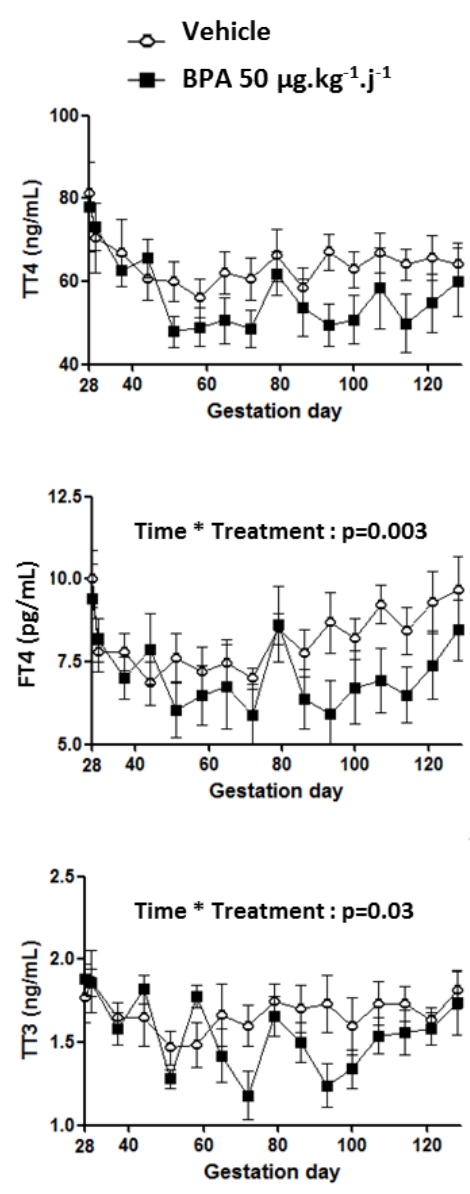
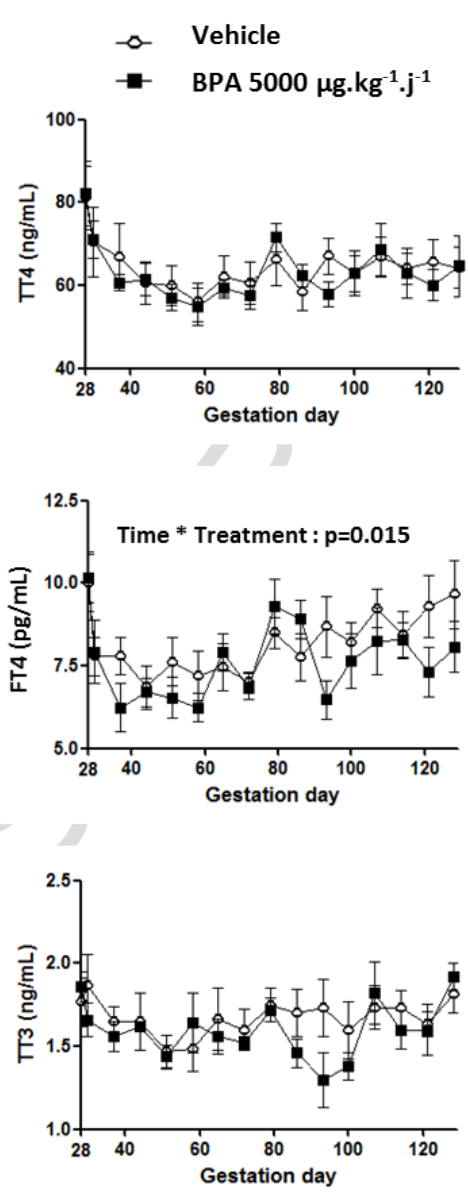

423

424

425

426

427

428

429

430

431

432

433

Fig. 4: time course of mean $( \pm \mathrm{SEM})$ total $\mathrm{T} 4$, free $\mathrm{T} 4$ and total $\mathrm{T} 3$ serum concentrations in pregnant ewes treated subcutaneously with vehicle $(n=6)$ or BPA $(0.5(\mu \mathrm{g} /(\mathrm{kg} . \mathrm{d}), \mathrm{n}=6) .50$ $\mu \mathrm{g} /(\mathrm{kg} . \mathrm{d}), \mathrm{n}=5$ or $5000 \mu \mathrm{g} /(\mathrm{kg} . \mathrm{d}), \mathrm{n}=5)$ from GD 28 to 132-134. Blood samples were collected on GD $28-30-37-44-51-58-65-72-79-86-93-100-107-114-121$ and 128 . Time * treatment significant interactions $(\mathrm{P}<0.05)$ were evidenced in several instances signifying that the time course of the hormones differed between the BPA and vehicle-treated animals. 


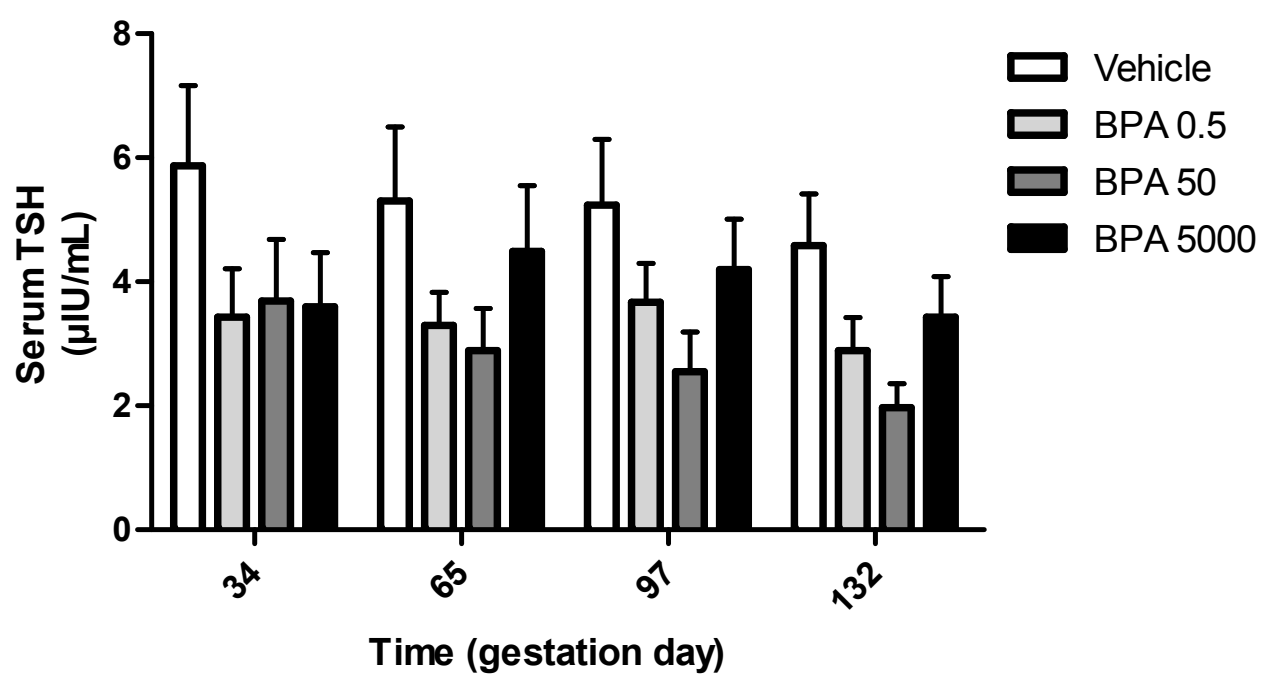

435 Fig. 5: mean ( \pm SEM) serum TSH concentrations in pregnant ewes treated subcutaneously with 436 vehicle (n=6) or BPA S.C. $(0.5 \mu \mathrm{g} /(\mathrm{kg} . \mathrm{d}), \mathrm{n}=6 ; 50 \mu \mathrm{g} /(\mathrm{kg} . \mathrm{d}), \mathrm{n}=5$ or $5000 \mu \mathrm{g} /(\mathrm{kg} . \mathrm{d}), \mathrm{n}=5)$ from 437 GD 28 to 132-134. Blood samples were collected on GD $34-65-97$ and 132. No significant 438 effect of BPA treatments could be evidenced.

Disruption of the maternal thyroid status was further characterized by measuring rT3 jointly to TT4 using HPLC/MS in samples collected from the $41^{\text {st }}$ day of gestation, i.e. after fT4 concentrations have started to decrease in the medium dose group. A treatment effect could be evidenced on TT4 concentrations with no interaction with the time. On rT3 profiles, a trend $(p=0.09)$ toward an interaction between time and treatment was evidenced suggesting that ratio (Fig. 6) was significantly affected by BPA exposure (interaction time $\mathrm{x}$ treatment $\mathrm{p}=0.04$ ) over the period considered. These modifications were due to differences between the control and medium dose groups with a time-dependent effect on the rT3 to TT4 ratio $(p=0.024)$ characterized by a higher rT3 to TT4 ratio in the BPA group from GD50 to 90, approximately. 

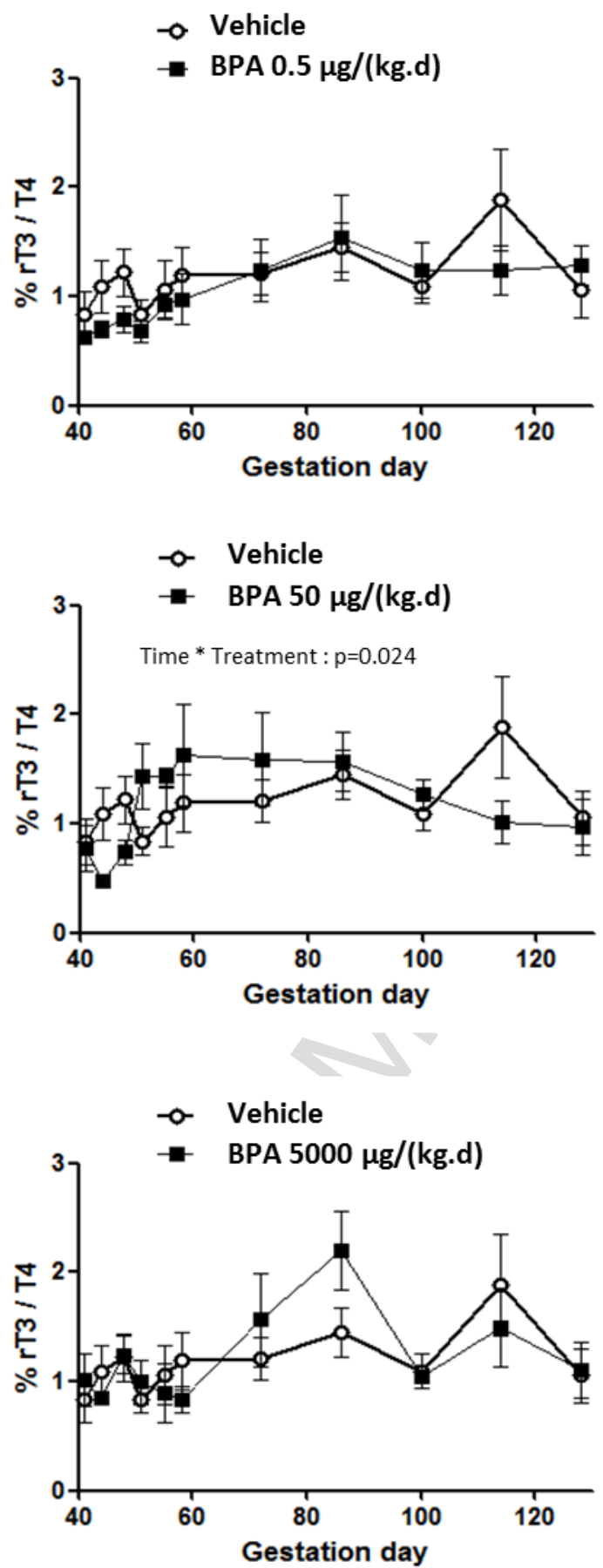

451 Fig. 6: time course of mean ( \pm S.E.M.) ratio (\%) of rT3 to total T4 serum concentrations measured by HPLC/MS in pregnant ewes treated subcutaneously with control or BPA $0.5-50$ and $5000 \mu \mathrm{g} /(\mathrm{kg} . \mathrm{d})$ from GD 40 to $132-134$. Blood samples were collected on GD $41-44$ $48-51-55-58-72-86-100-114$ and 128. A time * treatment significant interaction was

455 evidenced only in the groupe treated with the middle dose $(p=0.024)$ signifying that the time 456 course of the rT3/T4 ratio in this group differed from vehicle animals. 
457

458 Neither TT4 nor fT4 in fetal jugular blood (Fig. 7) were affected by BPA treatments at any of 459 the doses tested (individual comparison with the control group, $\mathrm{p}>0.05$ ). TT3 was never 460 detectable in fetal jugular blood.

A)

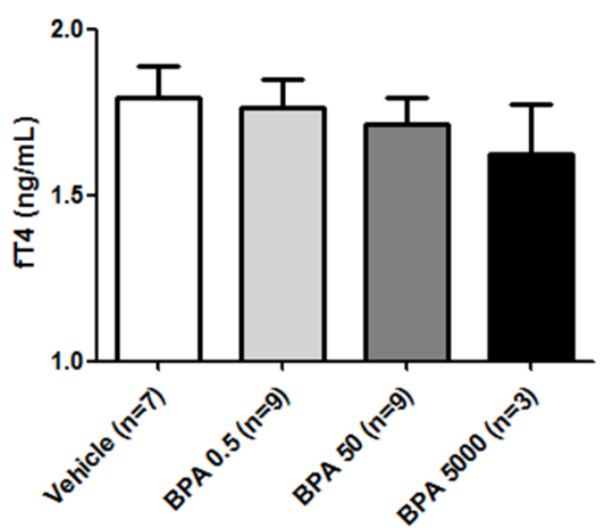

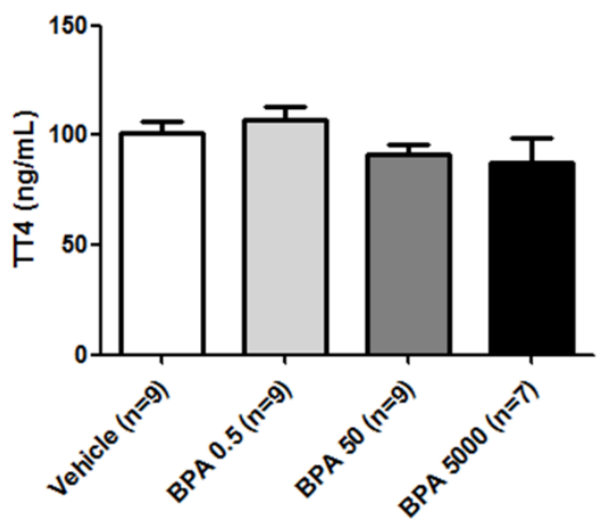

463 Fig. 7: mean ( \pm S.E.M.) free (A) and total (B) T4 serum concentrations measured by a RIA method in fetal jugular blood collected at GD132-134. Fetuses came from mothers treated with vehicle or BPA 0.5 - 50 and $5000 \mu \mathrm{g} /(\mathrm{kg} . \mathrm{d})$ from GD 28 to 132-134 S.C. Data were analyzed using a one factor ANOVA. No significant effect of the treatments could be evidenced ( $>0.05)$.

The thyroid hormone concentrations in cord blood were measured by HPLC/MS. TT3 in the concentrations and rT3/TT4 ratio could be evidenced in cord blood.

\section{Discussion}


473 Our study is one of the rare studies to directly assess the equivalence between a route of

474

475

476

477

478

479

480

481

482

483

484

485

486

487

488

489

490

491

492

493

494

495

496

497

exposure commonly used in experimental studies of BPA toxicity and the dietary route acknowledged as the main route of exposure for human populations. Our findings suggest that the bioavailability of BPA might be 30 fold lower when administered by dietary route than by subcutaneous route. Our current results indicate that the difference between the two routes of exposure is mainly related to the overall BPA exposure and much less to the peak serum concentrations. Our results also show that BPA-GLUC exposure, unlike that of BPA, is very similar for both routes of administration. BPA-GLUC is usually assumed to be devoid of biological activity. However, in some sensitive tissues, the balance between BPA detoxification by conjugation into BPA-GLUC and BPA-GLUC reactivation by deconjugation into BPA is in favor of deconjugation (Corbel et al., 2014). Although the mechanism enabling BPA-GLUC (a hydrophilic compound) to reach the intracellular space remains unknown, these observations indicate that internal exposure to BPA metabolite might also be of biological significance and should be more thoroughly considered in toxicological studies. Furthermore, it is noteworthy that BPA-GLUC blood profiles differ markedly after gavage administration as compared to the dietary one (Guignard et al., 2016). Thus when considering potential effects of BPA-GLUC, gavage might not be better than the subcutaneous route for evaluating BPA oral toxicity.

Our TK model enabled us to estimate the internal exposure of ewes treated by chronic exposure via the subcutaneous route. Interestingly, both the medium and low doses selected were predicted to reproduce BPA serum concentrations in ewes within the range of concentrations commonly reported in the most recent studies in pregnant women i.e., from $100 \mathrm{pg} / \mathrm{mL}$ (Teeguarden et al., 2016) to $4 \mathrm{ng} / \mathrm{mL}$ (Shekhar et al., 2016). However, in both those studies, free BPA would account for about $60-80 \%$ of total BPA while in our study the ratio of BPAGLUC to BPA was markedly in favor of BPA-GLUC in both the mother and the fetus at delivery, i.e.at least $24 \mathrm{~h}$ after the last BPA administration. 
498

499

500

501

502

503

504

505

506

507

508

509

510

511

512

513

514

515

516

517

518

519

520

521

Concerning fetal exposure, our exposure schemes made it possible to encompass the range of aglycone BPA concentrations reported in fetal compartments in humans, whether in amniotic fluid or cord blood. Indeed, for BPA, the geometric mean of about $4.8 \mathrm{ng} / \mathrm{mL}$ in the amniotic fluid of full-term human newborns (Shekhar et al., 2016) is similar to the concentrations measured in the amniotic fluid of lambs from the medium dose group in our study. Similarly, cord blood concentrations in human newborns (about $1.2 \mathrm{ng} / \mathrm{mL}$; Chevalier et al., 2015) are very close to the few measurable values obtained in the cord blood of lambs from our medium dose group. Our study evidenced a high accumulation rate of BPA-GLUC in the fetal compartment in agreement with other study with short term exposure. Indeed, in our current study, as in the short term fetal exposure study performed at GD120 (Corbel et al., 2013), amniotic fluid concentrations were about 4 fold lower than concentration in fetal blood (jugular or cord blood). However, in a first study with chronic gestational exposure (Viguié et al., 2013), BPA-GLUC concentrations in full term lambs were 2 fold higher in amniotic fluid than in fetal blood. The most likely explanation for such fetal age -dependent differences in fetal exposure to BPA-GLUC could rely on the ontogeny of UGT activity in the fetal sheep with a late rise toward the end of pregnancy (Pretheeban et al., 2011) similarly to human (Divakaran et al., 2014). The biological significance of the very high fetal exposure to BPA-GLUC produced in our sheep model and its relevance to humans remains to be elucidated. From this standpoint, it is noteworthy that some data in monkeys suggest that, similarly to what is observed in the ovine fetus, BPA-GLUC accumulates in the fetal compartment (Patterson et al., 2013).

BPA-SULF appeared to accumulate as well in the fetal compartment. However, it is noteworthy that it does not follow the same pattern in the fetal compartment than BPA-GLUC. BPA-SULF concentrations in the amniotic fluid are indeed about 10 fold lower than in the fetal compartment. This suggests that BPA-SULF might not be eliminated from the fetal blood 
522

523

524

525

526

527

528

529

530

531

532

533

534

535

536

537

538

539

540

541

542

543

544

545

546

through the kidney and thus the amniotic fluid or that BPA-SULF is very rapidly and efficiently cleared from the amniotic fluid.

Our results concerning the thyroid status of the mother reveal a certain degree of thyroid disruption oriented toward a decrease in concentrations of the circulating hormones, fT4 and TT3. The medium dose $(50 \mu \mathrm{g} /(\mathrm{kg} . \mathrm{d}))$ seemed to be pivotal as this level of BPA treatment significantly affected the time courses of both hormones. Interestingly, the time course of TT3, the biologically active hormone, tended to be significantly modified by our lowest dose $(0.5$ $\mu \mathrm{g} /(\mathrm{kg} . \mathrm{d}))$. This suggests that pregnant females might be sensitive to BPA-induced thyroid disruption even at environmentally-relevant exposure. Our study did not provide an assessment of the minimal active BPA dose. It is noteworthy however that the effect observed at our lowest dose are limited to a trend in TT3 decrease while both fT4 and TT3 were modified with the middle dose. Although our highest dose $(5000 \mu \mathrm{g} /(\mathrm{kg} . \mathrm{d}))$ enabled us to reproduce the hypothyroxinemia described in a previous study, surprisingly, modifications of the time course were only observed for fT4 and not for TT4. The fact that BPA induced a disrupting effect on some thyroid parameters at the medium and/or low doses but not at the high dose suggests a non-monotonic effect of BPA on thyroid function in pregnant animals. Nevertheless, this interpretation needs to be treated with caution and more doses and a larger number of animals would be required to evidence and characterize such a complicated dose-response relationship.

No effect of BPA treatments on fetal thyroid status could be evidenced in cord and jugular blood samples. This contrasts with our previous results in sheep (Viguié et al., 2013). One major difference between this study and the previous study in sheep is related to the gestational stage and fetal age and/or the different fetal exposure to BPA/BPA-GLUC. In our earlier experiment, the lambs were extracted at term, whereas in the current experiment they were extracted 10 to 14 days before term. Thus, the final stage of thyroid maturation might not yet have occurred in these animals. This explanation is fully consistent with the fact that TT3 could not be detected 
547

548

549

550

551

552

553

554

555

556

557

558

559

560

561

562

563

564

565

566

567

568

569

570

571

in the fetal blood samples. Indeed, TT3 concentration in the blood of sheep fetuses, as well as human fetuses (Fisher, 2002), is only detectable in the later stages of pregnancy (the last week for sheep; (Fisher et al., 1994). It is noteworthy that, in rodents, BPA-induced thyroid disruption due to maternal exposure was mainly evidenced during the postnatal period, which corresponds in this species to the final stage of maturation of thyroid function (Xu et al., 2007; Zoeller et al., 2005), i.e., equivalent to the two missing weeks required, in the current experiment, for the ewes to attain full term pregnancy.

Another explanation for such a discrepancy might arise from the difference in mineral supply provided to the animal. Indeed, in the current experiment, ewes received a pellet ration containing a mineral supply adapted to pregnancy requirements and thus enriched in mineral iodine (calcium iodate about $1.5 \mathrm{mg} /$ day) and selenium (sodium selenite about $0.62 \mathrm{mg} /$ day). Iodine supply might have somehow compensated at least in part the BPA-induced thyroid disruptive process or made the fetal thyroid function less sensitive to thyroid disruption. This kind of relationship between sensitivity to thyroid disruption and iodine status is supported by epidemiological observations in humans. The inverse maternal urinary BPA /newborn girl TSH relationship was shown to depend, at least in part, on the maternal iodine status in the human biomonitoring "HOME" survey (Romano et al., 2015), suggesting that the maternal iodine supply might somehow affect the sensitivity of the developing fetus to chemical thyroid disruption. Other examples of interaction between the iodine status and diverse thyroid stressors have been found in humans such as mercury in pregnant women (Llop et al., 2015) or perfluoroalkyl acids in anti-TPO antibody positive humans (Webster et al., 2016).

The mechanisms by which BPA exposure induces maternal thyroid disruption remain unclear. From our results, we could not get any evidence that either TSH secretion or TH binding to carrier serum proteins might be substantially altered in BPA-treated ewes. The absence of significant modifications of TSH in our BPA-treated pregnant ewes should not be considered 
as an ultimate proof that the thyroid axis alteration were of no potential functional

573

574

consequences. Disruption of thyroid homeostasis indeed occurs in the absence of modification of blood TSH in so called states of hypothyroxinemia (decreased free-T4 concentration with or without modifications of TSH). There are some experimental evidences that such maternal hypothyroxinemia might be of detrimental consequences on fetal neural development and as so should not be regarded as trivial (Morreale de Escobar et al., 2000; Lavado-Autric et al., 2003; Gilbert et al., 2012). Accordingly, some epidemiological surveys highlight a link between maternal hypothyroxinemia during pregnancy and increased risk of autism impaired psychomotor development, Attention Deficit Hyperactivity Disorder, language delay, lower mental scores (Zoeller et al., 2002; Henrichs et al., 2013; Román et al., 2013).

The balance between deiodinase activities converting $\mathrm{T} 4$ into either the bioactive $\mathrm{T} 3$ or inactiverT3 is a key factor in the maintenance of fetal thyroid homeostasis. This is why we measured rT3 and T4 concentrations in cord blood and in some bi-weekly maternal samples, using MS detection, in an attempt to gain new insights into the balance between T4 and rT3 and the potential mechanisms of BPA action. The results obtained with MS in maternal samples, collected from GD 41 to 128 , suggest that a modification of the deiodination balance, characterized by a time-dependent modulation of the rT3/TT4 ratio, occurred in mothers receiving the medium BPA dose compared to those in the vehicle group. The placenta is a key actor in fetal thyroid balance. It not only expresses deiodinases, in particular type 3 , to produce a balance between the active and inactive thyroid hormone supply to the fetus, it also synthesizes transthyretin which regulates the transplacental transfer of maternal thyroxine to the fetal compartments (Landers et al., 2009) and regulates iodide exchanges through NIS (Na/I symporter) expression. In vitro data suggest that the placenta is a sensitive target tissue for BPA, including at environmentally relevant doses (Mannelli et al., 2015; Sieppi et al., 2016; Tait et al., 2015). However, no evaluation of the impact of BPA on thyroid-relevant placental functions 
597

598

599

600

601

602

603

604

605

606

607

608

609

610

611

612

613

614

615

616

617

are currently available and there is no evidence that BPA can alter deiodinase expression and/or activity in any tissues. In the light of our current results indicating that in pregnant ewes BPA exposure modifies the balance between T4 and rT3 at a late stage of pregnancy, it could be very interesting to assess the effect of BPA on placental deiodinase activities.

\section{Conclusion}

Our study carried out in an animal model relevant to humans in terms of thyroid and gestation physiologies shows that BPA can affect maternal thyroid function and equilibrium during pregnancy. This effect was expressed at levels of internal exposure (as assessed by serum aglycone BPA concentrations) similar to those described in humans i.e. for BPA blood concentrations below the $\mathrm{ng} / \mathrm{ml}$ range. Although within the framework of this study, these maternal modifications could not be tied with alterations in some patterns of fetal $\mathrm{TH}$ serum concentration, the possibility remains that $\mathrm{TH}$ action and concentrations in target tissues, particularly in the brain, might have been affected. Interestingly, our data suggest that BPA exposure might somehow modify the deiodination balance, thus pinpointing a possible effect of BPA on the thyroid-related endocrine function of the placenta.

\section{$\underline{\text { Acknowledgements }}$}

We thank the INRA experimental unit of Domaine de Lafage for providing the animals and the staff from the ENVT sheep experimental unit for their involvement in animal care. 
618

619

620

621

622

623

624

625

626

627

628

629

630

631

632

633

634

635

636

637

638

639

640

641

642

This research did not receive any specific grant from funding agencies in the public, commercial, or not-for-profit sectors. D Guignard beneficiated from PhD Grant of the doctoral School SEVAB from the Institut National Polytechnique of Toulouse, France.

\section{$\underline{\text { References }}$}

Chapin, R.E., Adams, J., Boekelheide, K., Gray, L.E., Hayward, S.W., Lees, P.S.J., McIntyre, B.S., Portier, K.M., Schnorr, T.M., Selevan, S.G., Vandenbergh, J.G., Woskie, S.R., 2008. NTP-CERHR expert panel report on the reproductive and developmental toxicity of bisphenol A. Birth Defects Res. B. Dev. Reprod. Toxicol. 83, 157-395. doi:10.1002/bdrb.20147

Chevalier, N., Brucker-Davis, F., Lahlou, N., Coquillard, P., Pugeat, M., Pacini, P., PanaïaFerrari, P., Wagner-Mahler, K., Fénichel, P., 2015. A negative correlation between insulin-like peptide 3 and bisphenol $\mathrm{A}$ in human cord blood suggests an effect of endocrine disruptors on testicular descent during fetal development. Hum. Reprod. 30, 447-453. doi:10.1093/humrep/deu340

Chevrier, J., Gunier, R.B., Bradman, A., Holland, N.T., Calafat, A.M., Eskenazi, B., Harley, K.G., 2013. Maternal urinary bisphenol a during pregnancy and maternal and neonatal thyroid function in the CHAMACOS study. Environ. Health Perspect. 121, 138-144. doi:10.1289/ehp.1205092

Collet, S.H., Picard-Hagen, N., Viguié, C., Lacroix, M.Z., Toutain, P.-L., Gayrard, V., 2010. Estrogenicity of Bisphenol A: A Concentration-Effect Relationship on Luteinizing Hormone Secretion in a Sensitive Model of Prepubertal Lamb. Toxicol. Sci. 117, 5462. doi:10.1093/toxsci/kfq186

Corbel, T., Gayrard, V., Puel, S., Lacroix, M.Z., Berrebi, A., Gil, S., Viguié, C., Toutain, P.-L., Picard-Hagen, N., 2014. Bidirectional placental transfer of Bisphenol A and its main 
metabolite, Bisphenol A-Glucuronide, in the isolated perfused human placenta. Reprod. Toxicol. 47, 51-58. doi:10.1016/j.reprotox.2014.06.001

Corbel, T., Gayrard, V., Viguié, C., Puel, S., Lacroix, M.Z., Toutain, P.-L., Picard-Hagen, N., 2013. Bisphenol A Disposition in the Sheep Maternal-Placental-Fetal Unit: Mechanisms Determining Fetal Internal Exposure. Biol. Reprod. 89, 11. doi:10.1095/biolreprod.112.106369

Doerge, D.R., Twaddle, N.C., Vanlandingham, M., Fisher, J.W., 2010. Pharmacokinetics of bisphenol A in neonatal and adult Sprague-Dawley rats. Toxicol. Appl. Pharmacol. 247, 158-165. doi:10.1016/j.taap.2010.06.008

Fini, J.-B., Le Mevel, S., Turque, N., Palmier, K., Zalko, D., Cravedi, J.-P., Demeneix, B.A., 2007. An in vivo multiwell-based fluorescent screen for monitoring vertebrate thyroid hormone disruption. Environ. Sci. Technol. 41, 5908-5914.

Fisher, D.A., 2002. Endocrinology of fetal development, in: Williams Textbook of Endocrinology. Saunders, pp. 811-842.

Fisher, D.A., Dussault, J.H., Sack, J., Chopra, I.J., 1976. Ontogenesis of hypothalamic-pituitary--thyroid function and metabolism in man, sheep, and rat. Recent Prog. Horm. Res. 33, 59-116.

Fisher, D.A., Polk, D.H., Wu, S.Y., 1994. Fetal thyroid metabolism: a pluralistic system. Thyroid 4, 367-371.

Gayrard, V., Lacroix, M.Z., Collet, S.H., Viguié, C., Bousquet-Melou, A., Toutain, P.-L., Picard-Hagen, N., 2013. High bioavailability of bisphenol A from sublingual exposure. Environ. Health Perspect. 121, 951-956. doi:10.1289/ehp.1206339

Gilbert, M.E., Rovet, J., Chen, Z., Koibuchi, N., 2012. Developmental thyroid hormone disruption: Prevalence, environmental contaminants and neurodevelopmental consequences. Neurotoxicology 33, 842-852. 
668

669

670

671

672

673

674

675

676

677

678

679

680

681

682

683

684

685

686

687

688

689

690

691

692

Goto, Y., Kitamura, S., Kashiwagi, K., Oofusa, K., Tooi, O., Yoshizato, K., Sato, J., Ohta, S., Kashiwagi, A., 2006. Suppression of amphibian metamorphosis by bisphenol A and related chemical substances. J. Health Sci. 52, 160-168. doi:10.1248/jhs.52.160

Guignard, D., Gauderat, G., Gayrard, V., Lacroix, M.Z., Picard-Hagen, N., Puel, S., Toutain, P.-L., Viguié, C., 2016. Characterization of the contribution of buccal absorption to internal exposure to bisphenol A through the diet. Food Chem. Toxicol. doi:10.1016/j.fct.2016.04.004

Hard, G.C., 1998. Recent developments in the investigation of thyroid regulation and thyroid carcinogenesis. Environ. Health Perspect. 106, 427-436.

Heimeier, R.A., Das, B., Buchholz, D.R., Shi, Y.-B., 2009. The Xenoestrogen Bisphenol A Inhibits Postembryonic Vertebrate Development by Antagonizing Gene Regulation by Thyroid Hormone. Endocrinology 150, 2964-2973. doi:10.1210/en.2008-1503

Henrichs, J., Ghassabian, A., Peeters, R.P., Tiemeier, H., 2013. Maternal hypothyroxinemia and effects on cognitive functioning in childhood: how and why? Clin. Endocrinol. (Oxf.) 79, 152-162. doi:10.1111/cen.12227

Iwamuro, S., Sakakibara, M., Terao, M., Ozawa, A., Kurobe, C., Shigeura, T., Kato, M., Kikuyama, S., 2003. Teratogenic and anti-metamorphic effects of bisphenol A on embryonic and larval Xenopus laevis. Gen. Comp. Endocrinol. 133, 189-198. doi:10.1016/S0016-6480(03)00188-6

Kaneko, M., Okada, R., Yamamoto, K., Nakamura, M., Mosconi, G., Polzonetti-Magni, A.M., Kikuyama, S., 2008. Bisphenol A acts differently from and independently of thyroid hormone in suppressing thyrotropin release from the bullfrog pituitary. Gen. Comp. Endocrinol. 155, 574-580. doi:10.1016/j.ygcen.2007.09.009

Lacroix, M.Z., Puel, S., Collet, S.H., Corbel, T., Picard-Hagen, N., Toutain, P.L., Viguié, C., Gayrard, V., 2011. Simultaneous quantification of bisphenol A and its glucuronide 
693

694

695

696

697

698

699

700

701

702

703

704

705

706

707

708

709

710

711

712

713

714

715

716

metabolite (BPA-G) in plasma and urine: applicability to toxicokinetic investigations. Talanta 85, 2053-2059. doi:10.1016/j.talanta.2011.07.040

Landers, K.A., McKinnon, B.D., Li, H., Subramaniam, V.N., Mortimer, R.H., Richard, K., 2009. Carrier-Mediated Thyroid Hormone Transport into Placenta by Placental Transthyretin. J. Clin. Endocrinol. Metab. 94, 2610-2616. doi:10.1210/jc.2009-0048

Lavado-Autric, R., Ausó, E., García-Velasco, J.V., del Carmen Arufe, M., Escobar del Rey, F., Berbel, P., Morreale de Escobar, G., 2003. Early maternal hypothyroxinemia alters histogenesis and cerebral cortex cytoarchitecture of the progeny. J. Clin. Invest. 111, 1073-1082. doi:10.1172/JCI16262

Llop, S., Lopez-Espinosa, M.-J., Murcia, M., Alvarez-Pedrerol, M., Vioque, J., Aguinagalde, X., Julvez, J., Aurrekoetxea, J.J., Espada, M., Santa-Marina, L., Rebagliato, M., Ballester, F., 2015. Synergism between exposure to mercury and use of iodine supplements on thyroid hormones in pregnant women. Environ. Res. 138, 298-305. doi:10.1016/j.envres.2015.02.026

Mannelli, C., Ietta, F., Avanzati, A.M., Skarzynski, D., Paulesu, L., 2015. Biological Tools to Study the Effects of Environmental Contaminants at the Feto-Maternal Interface. DoseResponse 13. doi:10.1177/1559325815611902

Meeker, J.D., Calafat, A.M., Hauser, R., 2010. Urinary Bisphenol A Concentrations in Relation to Serum Thyroid and Reproductive Hormone Levels in Men from an Infertility Clinic. Environ. Sci. Technol. 44, 1458-1463. doi:10.1021/es9028292

Meeker, J.D., Ferguson, K.K., 2011. Relationship between Urinary Phthalate and Bisphenol A Concentrations and Serum Thyroid Measures in U.S. Adults and Adolescents from the National Health and Nutrition Examination Survey (NHANES) 2007-2008. Environ. Health Perspect. 119, 1396-1402. doi:10.1289/ehp.1103582 
Moriyama, K., Tagami, T., Akamizu, T., Usui, T., Saijo, M., Kanamoto, N., Hataya, Y., Shimatsu, A., Kuzuya, H., Nakao, K., 2002. Thyroid hormone action is disrupted by bisphenol $\mathrm{A}$ as an antagonist. J. Clin. Endocrinol. Metab. 87, 5185-5190. doi:10.1210/jc.2002-020209

Morreale de Escobar, G., Obregon, M.J., Escobar del Rey, F., 2000. Is Neuropsychological Development Related to Maternal Hypothyroidism or to Maternal Hypothyroxinemia? J. Clin. Endocrinol. Metab. 85, 3975-3987.

Patterson, T.A., Twaddle, N.C., Roegge, C.S., Callicott, R.J., Fisher, J.W., Doerge, D.R., 2013. Concurrent determination of bisphenol A pharmacokinetics in maternal and fetal rhesus monkeys. Toxicol. Appl. Pharmacol. 267, 41-48. doi:10.1016/j.taap.2012.12.006

Polk, D., Cheromcha, D., Reviczky, A., Fisher, D.A., 1989. Nuclear thyroid hormone receptors: ontogeny and thyroid hormone effects in sheep. Am. J. Physiol. 256, E543-549.

Richter, C.A., Birnbaum, L.S., Farabollini, F., Newbold, R.R., Rubin, B.S., Talsness, C.E., Vandenbergh, J.G., Walser-Kuntz, D.R., vom Saal, F.S., 2007. In vivo effects of bisphenol A in laboratory rodent studies. Reprod. Toxicol. Elmsford NY 24, 199.

Román, G.C., Ghassabian, A., Bongers-Schokking, J.J., Jaddoe, V.W.V., Hofman, A., de Rijke, Y.B., Verhulst, F.C., Tiemeier, H., 2013. Association of gestational maternal hypothyroxinemia and increased autism risk. Ann. Neurol. 74, 733-742. doi:10.1002/ana.23976

Romano, M.E., Webster, G.M., Vuong, A.M., Thomas Zoeller, R., Chen, A., Hoofnagle, A.N., Calafat, A.M., Karagas, M.R., Yolton, K., Lanphear, B.P., Braun, J.M., 2015. Gestational urinary bisphenol $\mathrm{A}$ and maternal and newborn thyroid hormone concentrations: The HOME Study. Environ. Res. 138, 453-460. doi:10.1016/j.envres.2015.03.003 
Roques, B.B., Lacroix, M.Z., Puel, S., Gayrard, V., Picard-Hagen, N., Jouanin, I., Perdu, E., Martin, P.G., Viguié, C., 2012. CYP450-dependent biotransformation of the insecticide fipronil into fipronil sulfone can mediate fipronil-induced thyroid disruption in rats. Toxicol. Sci. Off. J. Soc. Toxicol. 127, 29-41. doi:10.1093/toxsci/kfs094

Rubin, B.S., 2011. Bisphenol A: An endocrine disruptor with widespread exposure and multiple effects. J. Steroid Biochem. Mol. Biol. 127, 27-34. doi:10.1016/j.jsbmb.2011.05.002

Shekhar, S., Sood, S., Showkat, S., Lite, C., Chandrasekhar, A., Vairamani, M., Barathi, S., Santosh, W., 2016. Detection of phenolic endocrine disrupting chemicals (EDCs) from maternal blood plasma and amniotic fluid in Indian population. Gen. Comp. Endocrinol. doi:10.1016/j.ygcen.2016.05.025

Sheng, Z.-G., Tang, Y., Liu, Y.-X., Yuan, Y., Zhao, B.-Q., Chao, X.-J., Zhu, B.-Z., 2012. Low concentrations of bisphenol a suppress thyroid hormone receptor transcription through a nongenomic mechanism. Toxicol. Appl. Pharmacol. 259, 133-142. doi:10.1016/j.taap.2011.12.018

Sieppi, E., Vähäkangas, K., Rautio, A., Ietta, F., Paulesu, L., Myllynen, P., 2016. The xenoestrogens, bisphenol $\mathrm{A}$ and para-nonylphenol, decrease the expression of the ABCG2 transporter protein in human term placental explant cultures. Mol. Cell. Endocrinol. 429, 41-49. doi:10.1016/j.mce.2016.03.034

Sriphrapradang, C., Chailurkit, L., Aekplakorn, W., Ongphiphadhanakul, B., 2013. Association between bisphenol A and abnormal free thyroxine level in men. Endocrine 44, 441-447. doi:10.1007/s12020-013-9889-y

Sun, H., Shen, O.-X., Wang, X.-R., Zhou, L., Zhen, S., Chen, X., 2009. Anti-thyroid hormone activity of bisphenol A, tetrabromobisphenol $\mathrm{A}$ and tetrachlorobisphenol $\mathrm{A}$ in an improved reporter gene assay. Toxicol. In Vitro 23, 950-954. doi:10.1016/j.tiv.2009.05.004 
Tait, S., Tassinari, R., Maranghi, F., Mantovani, A., 2015. Bisphenol A affects placental layers morphology and angiogenesis during early pregnancy phase in mice. J. Appl. Toxicol. JAT 35, 1278-1291. doi:10.1002/jat.3176

Taylor, J.A., vom Saal, F.S., Welshons, W.V., Drury, B., Rottinghaus, G., Hunt, P.A., Toutain, P.-L., Laffont, C.M., VandeVoort, C.A., 2011. Similarity of Bisphenol A Pharmacokinetics in Rhesus Monkeys and Mice: Relevance for Human Exposure. Environ. Health Perspect. 119, 422-430. doi:10.1289/ehp.1002514

Teeguarden, J.G., Twaddle, N.C., Churchwell, M.I., Doerge, D.R., 2016. Urine and serum biomonitoring of exposure to environmental estrogens I: Bisphenol A in pregnant women. Food Chem. Toxicol. 92, 129-142. doi:10.1016/j.fct.2016.03.023

Terrien, X., Fini, J.-B., Demeneix, B.A., Schramm, K.-W., Prunet, P., 2011. Generation of fluorescent zebrafish to study endocrine disruption and potential crosstalk between thyroid hormone and corticosteroids. Aquat. Toxicol. 105, 13-20. doi:10.1016/j.aquatox.2011.04.007

Tominaga, T., Negishi, T., Hirooka, H., Miyachi, A., Inoue, A., Hayasaka, I., Yoshikawa, Y., 2006. Toxicokinetics of bisphenol A in rats, monkeys and chimpanzees by the LCMS/MS method. Toxicology 226, 208-217. doi:10.1016/j.tox.2006.07.004

Viguié, C., Collet, S.H., Gayrard, V., Picard-Hagen, N., Puel, S., Roques, B.B., Toutain, P.-L., Lacroix, M.Z., 2013. Maternal and fetal exposure to bisphenol a is associated with alterations of thyroid function in pregnant ewes and their newborn lambs. Endocrinology 154, 521-528. doi:10.1210/en.2012-1401

vom Saal, F.S., Akingbemi, B.T., Belcher, S.M., Birnbaum, L.S., Crain, D.A., Eriksen, M., Farabollini, F., Guillette, L.J., Hauser, R., Heindel, J.J., Ho, S.-M., Hunt, P.A., Iguchi, T., Jobling, S., Kanno, J., Keri, R.A., Knudsen, K.E., Laufer, H., LeBlanc, G.A., Marcus, M., McLachlan, J.A., Myers, J.P., Nadal, A., Newbold, R.R., Olea, N., Prins, 
G.S., Richter, C.A., Rubin, B.S., Sonnenschein, C., Soto, A.M., Talsness, C.E., Vandenbergh, J.G., Vandenberg, L.N., Walser-Kuntz, D.R., Watson, C.S., Welshons, W.V., Wetherill, Y., Zoeller, R.T., 2007. Chapel Hill bisphenol A expert panel consensus statement: integration of mechanisms, effects in animals and potential to impact human health at current levels of exposure. Reprod. Toxicol. Elmsford N 24, 131-138. doi:10.1016/j.reprotox.2007.07.005

Vom Saal, F.S., VandeVoort, C.A., Taylor, J.A., Welshons, W.V., Toutain, P.-L., Hunt, P.A., 2014. Bisphenol A (BPA) pharmacokinetics with daily oral bolus or continuous exposure via silastic capsules in pregnant rhesus monkeys: Relevance for human

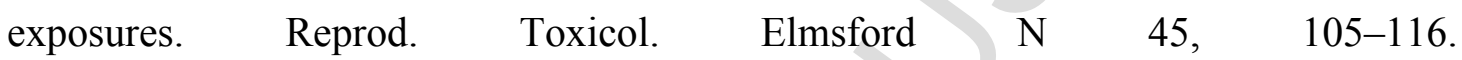
doi:10.1016/j.reprotox.2014.01.007

Wang, N., Zhou, Y., Fu, C., Wang, H., Huang, P., Wang, B., Su, M., Jiang, F., Fang, H., Zhao, Q., Chen, Y., Jiang, Q., 2015. Influence of Bisphenol A on Thyroid Volume and Structure Independent of Iodine in School Children. PLOS ONE 10, e0141248. doi:10.1371/journal.pone.0141248

Wang, T., Lu, J., Xu, M., Xu, Y., Li, M., Liu, Y., Tian, X., Chen, Y., Dai, M., Wang, W., Lai, S., Bi, Y., Ning, G., 2013. Urinary bisphenol a concentration and thyroid function in Chinese adults. Epidemiol. Camb. Mass 24, 295-302. doi:10.1097/EDE.0b013e318280e2f

Webster, G.M., Rauch, S.A., Marie, N.S., Mattman, A., Lanphear, B.P., Venners, S.A., 2016. Cross-Sectional Associations of Serum Perfluoroalkyl Acids and Thyroid Hormones in U.S. Adults: Variation According to TPOAb and Iodine Status (NHANES 2007-2008). Environ. Health Perspect. 124, 935-942. doi:10.1289/ehp.1409589

Wu, K.-M., Farrelly, J.G., 2006. Preclinical development of new drugs that enhance thyroid hormone metabolism and clearance: inadequacy of using rats as an animal model for 
predicting human risks in an IND and NDA. Am. J. Ther. 13, 141-144. doi:10.1097/01.mjt.0000209673.01885.b0

Xu, X., Liu, Y., Sadamatsu, M., Tsutsumi, S., Akaike, M., Ushijima, H., Kato, N., 2007. Perinatal bisphenol A affects the behavior and SRC-1 expression of male pups but does not influence on the thyroid hormone receptors and its responsive gene. Neurosci. Res. 58, 149-155. doi:10.1016/j.neures.2007.02.011

Yang, J., Chan, K.M., 2015. Evaluation of the toxic effects of brominated compounds (BDE47, 99, 209, TBBPA) and bisphenol A (BPA) using a zebrafish liver cell line, ZFL. Aquat. Toxicol. 159, 138-147. doi:10.1016/j.aquatox.2014.12.011

Zoeller, R.T., Bansal, R., Parris, C., 2005. Bisphenol-A, an environmental contaminant that acts as a thyroid hormone receptor antagonist in vitro, increases serum thyroxine, and alters RC3/neurogranin expression in the developing rat brain. Endocrinology 146, 607-612. doi:10.1210/en.2004-1018

Zoeller, T.R., 2010. Environmental chemicals targeting thyroid. Horm. Athens 9, 28-40.

Zoeller, R.T., Dowling, A.L.S., Herzig, C., Iannacone, E.A., Gauger, K.J., Bansal, R., 2002. Thyroid Hormone, Brain Development, and the Environment. Environmental health perspectives 110 . 


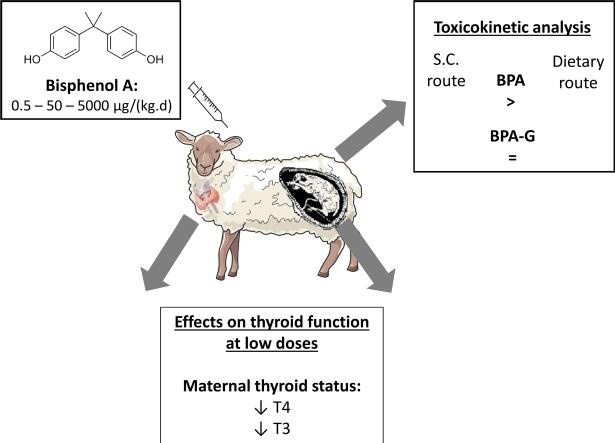

